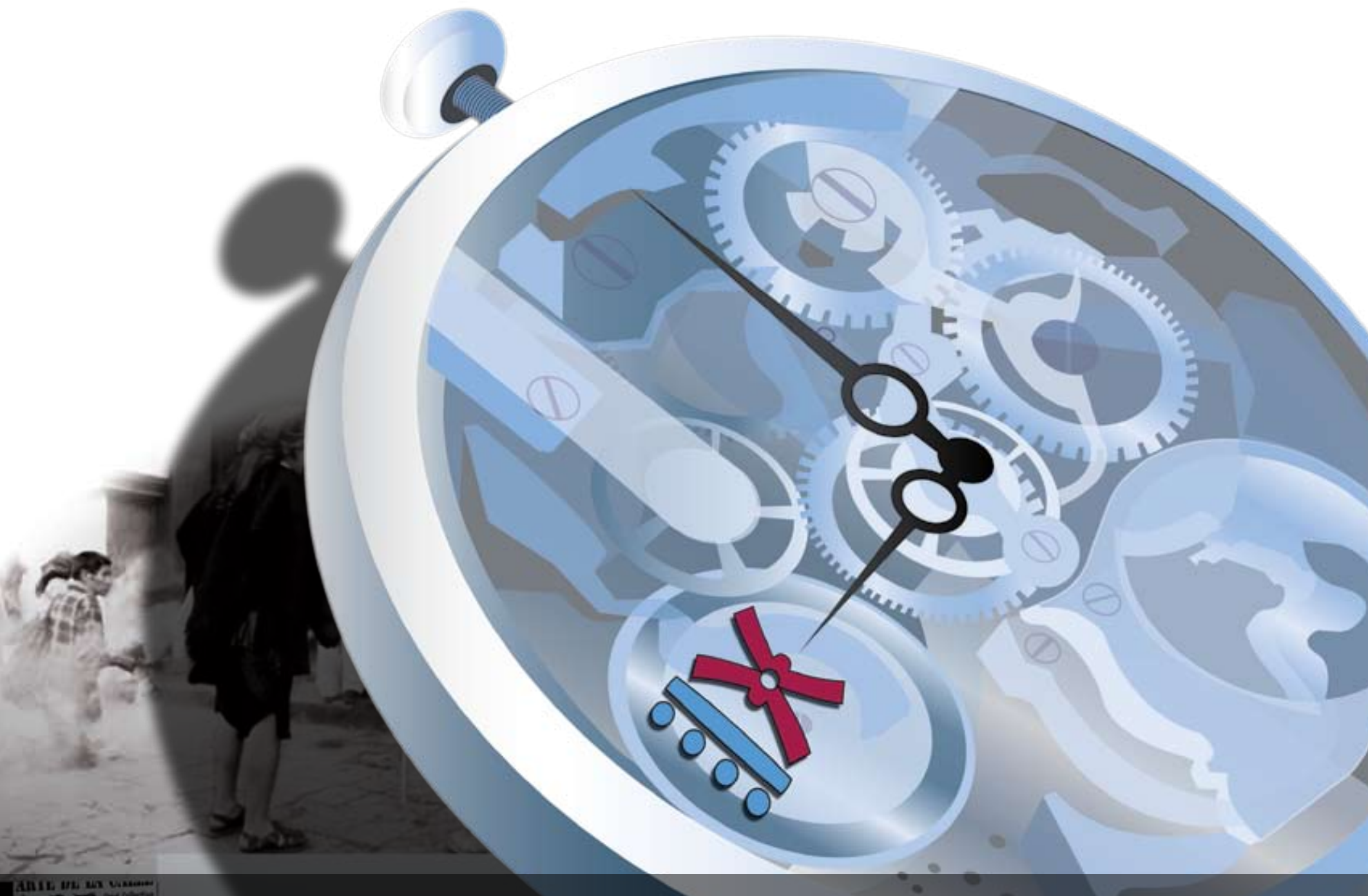

$9^{\circ}$ C O N G R E S O 2. CENTROAMERICANO DE H ISTO R I A
Universidad de Costa Rica

ISSN 1409- 469X

Fecha de recepción: 15 de mayo 2008 Fecha de aceptación: 30 de mayo 2008

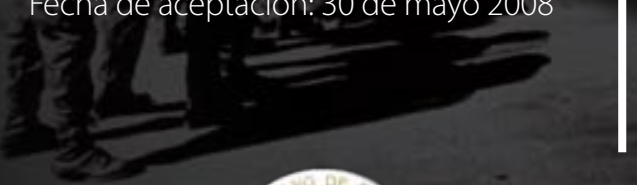

\section{El Modelo Centroamericano de Transición} Política: Definición y Análisis

Miembros del Consejo Editorial:

Dr. Ronny Viales, Dr. Juan José Marín

Editores Técnicos:

Allan Fonseca, Andrés Cruz, Gabriela Soto
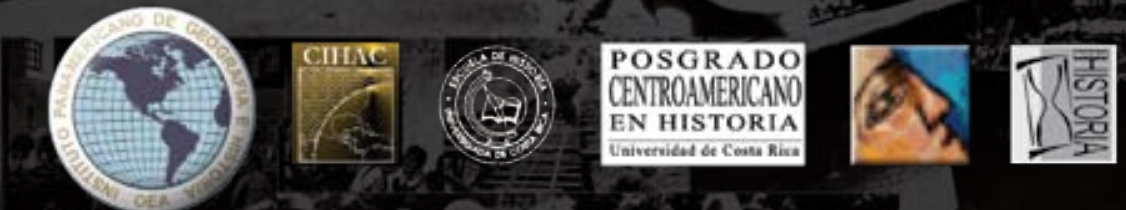
Indexaciones: Repositorio de Revistas UCR, DIALNET, Latindex, REDALYC Directorio y recolector de recursos digitales del Ministerio de Cultura de España, Directory of Open Access Journals. Diálogos Revista Electrónica de Historia ISSN 1409-469X. Número especial 2008. Dirección web: http://historia.fcs.ucr.ac.cr/dialogos.htm

\title{
El Modelo Centroamericano de Transición Política: Definición y Análisis
}

\author{
Jesús Fernández García
}

\begin{abstract}
Licenciado en Historia y Diploma de Estudios Avanzados en Historia Contemporánea. Miembro del Grupo de Estudios “Historia Actual” (PAI-HUM315), Universidad de Cádiz (España). http://www.uca.es/geha E-mail: jesus.fernandez@uca.es
\end{abstract}




\section{Introducción:}

Durante los años noventa Centroamérica ha vivido dos procesos simultáneos, el fin de los conflictos que desangraron la región durante los años ochenta, tras llevar a cabo exitosos procesos de paz, y una serie de procesos de transición hacia la democracia liberal.

El objetivo del presente trabajo es el análisis de estos procesos de transición, con la pretensión de definir y caracterizar lo que podríamos llamar el modelo centroamericano de transición política como un modelo claramente diferenciado, dentro de las líneas fundamentales de los procesos de transición, y definido principalmente por la situación de guerra abierta que introduce una nueva variable. Un modelo en el que se unifican proceso de paz y proceso de transición.

Con el objeto de realizar el análisis de Centroamérica en su conjunto, agruparemos a los seis países de la región por sus condiciones internas en el momento de dar paso a los procesos de transición, con la intención de buscar las similitudes, las zonas de convergencia que nos permitan definir el modelo de transición centroamericano, sin olvidarnos de las peculiaridades de cada país (Fig. 1).

En base a esto y como primer agrupamiento nos encontramos con dos realidades diferentes, la de aquellos estados que afrontan la transición en condiciones de guerra abierta, que serían El Salvador, Guatemala, Nicaragua y Panamá y aquellos que lo afrontan en condiciones de paz, aún siendo habitual la conflictividad social o política, en él estaría Honduras. Costa Rica, quedaría como la excepción ya que no vivió un proceso de transición interno al contar con una larga tradición de democracia liberal y pacifismo, aunque sí se vio afectada por los cambios ocurridos en la región. 


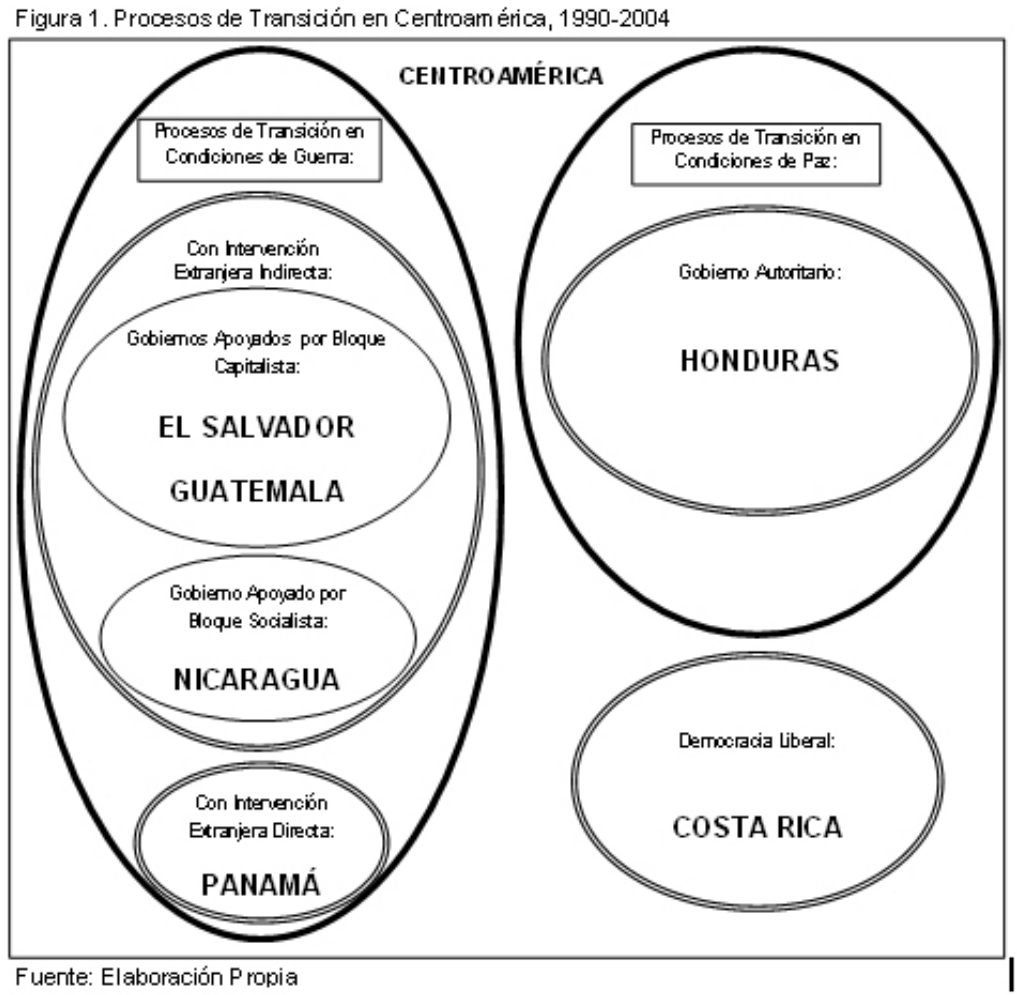

Del primer grupo debemos separar los países en los que se produce intervención extranjera de forma indirecta, como son los casos de Nicaragua, El Salvador y Guatemala, es decir, a partir de grupos armados apoyados por las dos grandes potencias, diferenciando aquí los dos países cuyos gobiernos son apoyados por el bloque capitalista, con EEUU como garante, que son El Salvador y Guatemala y por otra parte Nicaragua cuyo gobierno es apoyado por el bloque socialista, sobre todo por la URSS y Cuba como su agente en la zona. Por otra parte tenemos a Panamá como país que por sus condicionantes geopolíticos, fundamentalmente la existencia del canal, sufre la intervención directa por parte de una potencia extranjera, EEUU, que invade el país en 1989, dando paso a una transición impuesta.

En cuanto a Honduras, que afronta su proceso de transición en condiciones pacíficas, transita de un gobierno autoritario apoyado por occidente, sobre todo por EEUU que utiliza el país como centro de sus operaciones en la zona en los ochenta, fundamentalmente para dar cobertura a la Contra que llevará a cabo una agresión constante contra la Nicaragua sandinista, 
hacia una democracia liberal.

El presente trabajo se centrará en analizar los países que viven esta transición como parte de un proceso que también significa el fin de la guerra, El Salvador, Guatemala y Nicaragua, ya que estos tres, a nuestro juicio, poseen una serie de características comunes que hacen de ellos tres transiciones que pese a sus particularidades y diferencias, son exponentes de un mismo tipo de transición, componen un modelo reconocible y bien definido, cuya principal diferencia respecto al resto será la simultaneación de dos procesos, lo que configura una doble transición, un proceso de paz que posibilita la transición de la guerra a la paz y una transición política desde un sistema no democrático a un sistema de democracia liberal.

Es decir, las transiciones de El Salvador, Guatemala y Nicaragua, tienen características propias, son fruto de unas condiciones políticas, económicas y sociales diferentes y no queremos soslayar estas diferencias que hacen de cada proceso una experiencia única, merecedora de un pormenorizado estudio, pero ese no será nuestro objetivo, nosotros intentaremos definir las similitudes de los tres procesos en base a unas variables que se dan en cada uno de ellos y que hacen que podamos hablar de un modelo centroamericano de transición política, intentaremos definir este modelo, marcado por la unificación de proceso de paz y transición política, un modelo en el que se transita más que de la dictadura a la democracia, de la guerra a la democracia, y mostrar las características comunes y las diferencias con respecto al resto de transiciones o modelos de transición.

No son estos tres países los únicos que viven en los años noventa un proceso de transición en Centroamérica, pero si son los que presentan factores que los convierten en un modelo único y novedoso, mientras los otros países viven procesos identificables con modelos ya experimentados en otras zonas y épocas.

Honduras vive un proceso de transición pero no una guerra abierta, el gobierno autoritario conservador de Honduras apenas tiene que enfrentarse con grupos guerrilleros de izquierda, que en ningún momento suponen un peligro real para la estabilidad del régimen, por tanto nos encontramos con un proceso de transición identificable con los del resto de Latinoamérica o Europa Meridional, un proceso de transición de un sistema autoritario represivo a una democracia liberal. Panamá vive también un proceso de transición desde un gobierno autoritario clásico, la dictadura personalista de Noriega, a un sistema democrático, pero este se da tras la invasión de una potencia exterior que impone la democracia, es decir, estaría más cerca del modelo de 
instauración de la democracia que de una transición tal como éstas se han dado en los últimos treinta años. Instauración de la democracia por una potencia invasora, este fue el modelo llevado a la práctica tras la segunda guerra mundial en Europa Occidental, del que la Alemania de la postguerra es el paradigma, modelo que tras años de ostracismo ha vuelto con fuerza a la primera línea, ya que es el que EEUU intenta aplicar, hasta el momento con poco éxito, en sus últimas invasiones de Afganistán e Iraq, un modelo que presenta una situación de guerra, pero no una guerra interna entre los que serán luego actores principales de la transición y su consecuente régimen postransicional, sino una guerra de invasión en la que el invasor exterior marcará el sistema posterior. También en El Salvador, Guatemala y Nicaragua se dan intervenciones extranjeras, pero estas serán indirectas, es decir, en apoyo a alguna de las facciones contendientes, y esta potencia, EEUU, influirá tremendamente, pero no determinará, el rumbo del proceso de paz y de la transición.

Costa Rica sería, como casi siempre que se analiza la región, la eterna excepción, no vive lo que podríamos denominar una transición política, aunque es evidente que de la misma forma que le afecta la llamada crisis centroamericana en los ochenta, encontrándose en medio de una región en guerra, le afectará en los noventa la situación de procesos de paz y transiciones, de cambios políticos que transforman a fondo la zona y por tanto, afectan también a este país, a su economía y sus condicionantes sociales, entre otras situaciones pasando de acoger a refugiados de guerra a acoger emigración económica. Por ello, Costa Rica es un caso único y distinto que merece un análisis concreto, que sería interesante para definir cómo afectan en su interior los cambios en su entorno.

La definición de este modelo de transición centroamericano tendrá dos utilidades fundamentales, por una parte nos proporcionará un marco desde el que analizar los procesos de transición de la zona y por consiguiente nos dará la clave para analizar las características y problemas que presentan las democracias de esos países hoy en día, esas democracias que por sus especiales características llamaremos democracias postransicionales. Por otra parte el conocimiento a fondo del modelo nos abrirá la puerta a la posible aplicación futura en situaciones parecidas, es decir, en procesos de transición que deban partir de una guerra civil, debiendo aplicar un proceso de paz y una transición en la que el sector gubernamental deba dejar un espacio político a sus antiguos enemigos, como posiblemente será en un futuro, esperemos que 
cercano, el caso de Colombia, o de algunos de los países africanos que viven actualmente un conflicto interno.

Estas transiciones centroamericanas se enmarcan en lo que autores como Samuel Huntington o John Markoff han venido en llamar una nueva ola de democratizaciones, que incluiría los procesos llevados a cabo en la Europa Meridional, América Latina y muchos de los países del hasta entonces bloque socialista, procesos en los que diferentes países han pasado de sistemas de gobierno autoritarios o no democráticos hacia sistemas de gobierno homologables con las democracias occidentales o liberales.

No entraremos aquí, por razones evidentes de espacio, en la discusión sobre las diferentes concepciones de la democracia, utilizaremos el término democracia en base a una definición procedimental, dejando fuera las condiciones sociales y económicas que harían efectivos esos procedimientos y por lo tanto entenderemos por democracia la democracia liberal instaurada en los países occidentales.

\section{El Modelo Centroamericano de Transición Política}

La variable fundamental, que a la vez iguala en gran medida a los tres procesos y convierte a este modelo en diferente del resto, es la presencia de una guerra abierta en el momento de efectuarse el proceso de transición. El Salvador, Guatemala y Nicaragua viven en los ochenta una cruel guerra civil en sus territorios. Es a partir de 1990 cuando, primero Nicaragua, luego El Salvador y finalmente Guatemala llevan a cabo un proceso de paz que transporta a estos países de la guerra a la paz y al mismo tiempo un proceso de transición que les lleva de sistemas de gobierno no democráticos, si tomamos como modelo de democracia la democracia liberal occidental, a convertirse en democracias liberales homologables con las occidentales. Es este factor el que hace de este modelo un caso único frente a los procesos de transición en Europa Meridional, el resto de Latinoamérica y Europa del Este y a la vez es el factor que unifica a los tres procesos individuales, ya que la guerra introduce variables que no se dan en otras transiciones como: La tutela internacional directa de estos procesos a través de misiones de verificación de Naciones Unidas, la necesidad del cumplimiento de unos acuerdos de paz, la desmilitarización, la desmovilización de las fuerzas irregulares y la integración de éstas en la vida civil. A la vez 
la situación de guerra potencia algunas de las características comunes al resto de modelos de transición como: la influencia decisiva del contexto internacional, el problema de la impunidad ante las violaciones de los Derechos Humanos, y la aceptación del binomio democracia-mercado (Fig. 2).

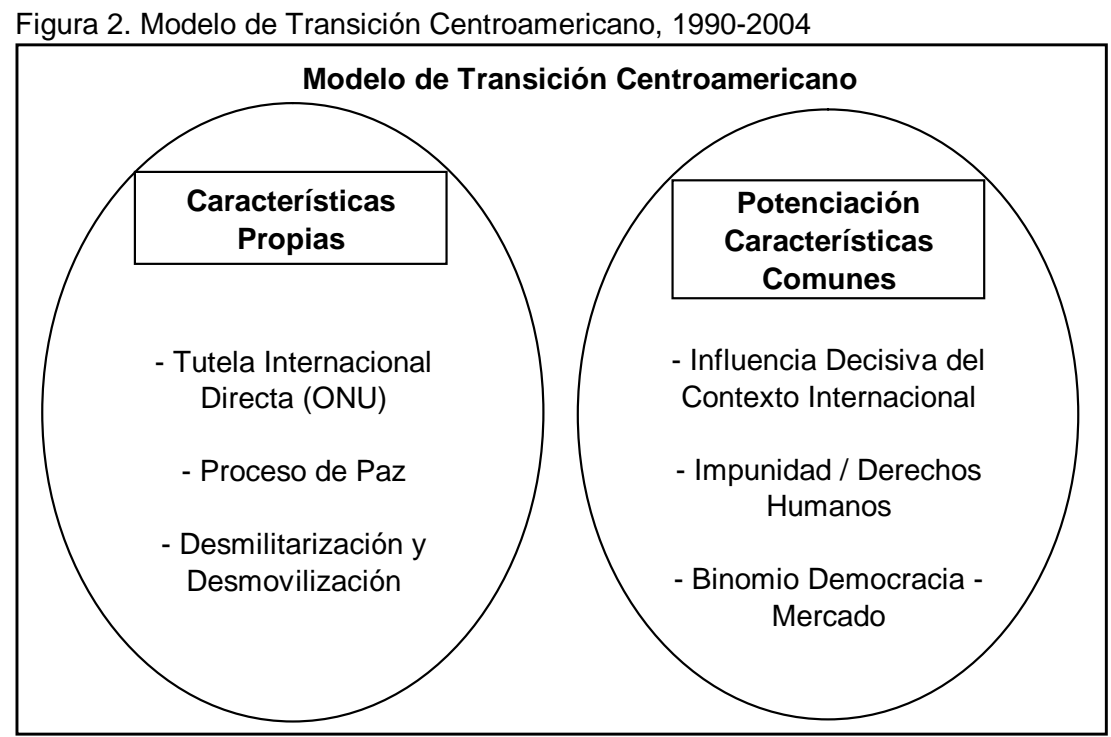

Fuente: Elaboración Propia

Por lo tanto, por encima de las diferencias que señalaremos y que sin duda son muchas en los tres casos, sobre todo entre El Salvador y Guatemala por una parte y Nicaragua por otra, existen, a nuestro entender, suficientes factores de coincidencia para hablar de un modelo de transición centroamericano, marcado por la unificación de proceso de paz y transición política, por esta doble transición de la guerra a la paz y de un sistema no democrático a la democracia liberal. Un modelo en el que se transita más que de la dictadura a la democracia, de la guerra a la democracia.

Este modelo centroamericano de transición política puede suponer un modelo factible para el análisis de procesos transicionales que se lleven a cabo en el futuro en otras regiones, ya que transiciones políticas en condiciones de guerra y en las que sea necesario llevar a cabo simultáneamente un proceso de paz y un proceso de transición hacia sistemas democráticos serán probablemente el escenario que nos encontremos en el futuro en algunos países de África que se encuentran actualmente en guerra y en países como Colombia, donde tarde o temprano se deberán retomar de forma responsable las conversaciones de paz entre las FARC y el gobierno, teniendo 
que producirse un proceso muy parecido al centroamericano, con desarmes, desmovilizaciones de grupos armados y desmilitarización de la sociedad colombiana y todo bajo la atenta mirada de EEUU y de observadores de Naciones Unidas. Ésta al menos, podría ser la salida más deseable.

Por lo tanto, la aportación de Centroamérica al modelo transicional general es mayor del que hasta ahora se ha estimado y puede que albergue una gran potencialidad, no sólo como modelo de democratización, sino también de pacificación y resolución de conflictos futuros.

\section{$\underline{\text { La influencia del contexto internacional }}$}

Es evidente la influencia de la situación internacional en los procesos transicionales llevados a cabo en las últimas tres décadas. Se ha creado un clima internacional propicio a favorecer estos procesos, lo que en parte ha llevado a esta ola democratizadora. Los regímenes dictatoriales centroamericanos, como los de todos los países latinoamericanos, cumplieron una misión, la de servir como freno ante el peligro de expansión del comunismo, que avanzaba siguiendo el ejemplo de la revolución cubana y luego de los Sandinistas. Estos regímenes aseguraban así el sistema y con ello los privilegios de las oligarquías locales y las multinacionales estadounidenses. En los años ochenta, con el paulatino desprestigio de la alternativa que representaba el bloque socialista y finalmente tras la caída del muro de Berlín, era posible el lavado de cara, su utilidad ya había pasado, habían cumplido a la perfección su cometido, era el momento de una renovación en las formas de control de esos países por parte de las potencias hegemónicas, sobre todo EEUU, potencia regional indiscutible en el continente.

En las transiciones de la Europa Meridional, los principales tutores o garantes del proceso habían sido, como no podía ser de otra forma, las potencias europeas occidentales, bajo la atenta mirada de EEUU como superpotencia dirigente del bloque capitalista. Un papel destacado tuvo Alemania, sobre todo con el apoyo dado a los partidos socialistas español, portugués y griego desde el Partido Socialdemócrata Alemán, estas potencias por tanto, garantizan al proceso apoyo internacional para los líderes que fomentan la democratización y la futura incorporación en plenitud de derechos en las dos organizaciones fundamentales para Europa Occidental en esos años, la OTAN y la Comunidad Económica Europea (CEE).

Por tanto, había un clima internacional favorable a las transiciones europeas de los setenta, las potencias occidentales veían con buenos ojos la asimilación de estos países a sus sistemas y 
para el bloque soviético no suponía cambios en el equilibrio geopolítico, por el contrario, podrían normalizar sus relaciones diplomáticas y comerciales y tener pares ideológicos en la legalidad.

De la misma forma, el proceso democratizador en Centroamérica cuenta con la vigilancia cercana de la potencia del norte, que actúa sin cortapisas en su "patio trasero". Tras el visto bueno de Washington, sólo concedido tras el fin de la guerra fría, Naciones Unidas tuvo un papel esencial en las negociaciones de los acuerdo de paz, haciendo de intermediario y forzando a las partes al entendimiento. Es evidente que esta tutela internacional facilitó enormemente las negociaciones y garantizó a las partes que los acuerdos serían respetados en lo fundamental, pero no deja de ser, en cierta forma, una pérdida de soberanía ante sus tutores internacionales, garantes del proceso de transición, que aunque no de forma explícita, pusieron coto a lo negociable, dejando fuera de la mesa cualquier propuesta que no respetara los principios de democracia liberal, sistema capitalista de mercado y adhesión estratégica al bloque occidental, tema fundamental en esos años aún marcados por las décadas de guerra fría. Aunque posiblemente esas garantías externas contra posibles intentos de cambio revolucionario, son las que posibilitaron que los elementos reaccionarios y las élites económicas accedieran a la negociación.

La propia Naciones Unidas fue la encargada de vigilar y verificar el cumplimiento de los acuerdos de paz, para ello puso en marcha tres Operaciones para el Mantenimiento de la Paz (OMP), la primera de ellas fue ONUCA, cuyo cometido era el envío de observadores de Naciones Unidas a Centroamérica, en principio en toda Centroamérica, para verificar los acuerdos de Esquípulas II, finalmente se centra sobre todo en Nicaragua, esta misión permanece activa desde diciembre de 1989 hasta diciembre de 1991. Con el avance de las conversaciones de paz en El Salvador se acuerda crear una misión de verificación auspiciada por Naciones Unidas, ONUSAL, que tras los acuerdos de paz se encargará de la vigilancia de dichos acuerdos, bajo mando militar español esta misión se desarrollará desde julio de 1991 hasta abril de 1995. La tercera de las misiones será MINUGUA, que tendrá como función también la verificación de los acuerdos de paz, llevándose a cabo desde 1994 a $2005 .{ }^{1}$

Es fundamental también para las nuevas democracias el impulso que supone la plena integración regional, cuya mejor muestra es la integración de las nuevas democracias de la

$1 \quad$ Para un análisis de las tres misiones, sobre todo de la participación española en ellas ver: BLÁZQUEZ VILAPLANA, Belén, La participación española en las operaciones de paz en Centroamérica: especial referencia a ONUSAL y ONUCA, [Publicación en línea], Centro de Estudios y Análisis de Seguridad, Universidad de Granada, 2002. Disponible desde Internet en: <http://www.ugr.es/ ceas> [Con acceso el 13/04/2008] 
Europa meridional en la entonces Comunidad Económica Europea, ello generó una ingente cantidad de beneficios para estos países, en cuanto a estabilidad económica y política, y sobre todo en cuanto a apoyo para posibilitar el desarrollo económico del país y así consolidar estas jóvenes democracias. La Unión Europea se convirtió en un marco que garantizaba la viabilidad política y económica de estos países antes considerados inestables o inseguros y con regímenes faltos de legitimidad internacional. No es aventurado afirmar que la integración plena en la UE es la verdadera piedra angular que ha posibilitado la pertenencia sin discusiones de Portugal, España y Grecia al club de los países democráticos y desarrollados.

Pero no hay paralelo en Latinoamérica de este apoyo que posibilite el desarrollo y la integración y menos aún en Centroamérica. EEUU, como potencia regional, podría haber utilizado su influencia en Centroamérica para promocionar la democracia en la zona, pero en vez de ello se dedicó a intervenir para proteger sus intereses, apoyando a regímenes dictatoriales o imponiéndolos directamente, y tras la transición sólo ha seguido preocupándose de sus intereses comerciales, impulsando programas de integración de mercados a nivel continental, no centrados en posibilitar el desarrollo y la integración económica de los países menos desarrollados, como la UE, sino imponiendo medidas librecambistas que benefician exclusivamente a sus multinacionales.

Por otra parte, los intentos de integración regional al margen de EEUU no han tenido éxito, ya sea por problemas entre los diferentes países, como por la oposición de EEUU y los organismos internacionales que este controla, que intentan impedir que estos avancen hacia la construcción de bloques fuertes supongan un peligro para su hegemonía continental. El MERCOSUR es el ejemplo paradigmático de integración con pretensiones amplias pero realidades siempre postergadas. En cuanto a Centroamérica, la Integración Centroamericana no ha tenido un desarrollo suficiente, quedándose normalmente en declaraciones de buenas intenciones.

Desde luego, estos intentos integradores ni han tenido, ni pueden tener, un núcleo duro de países desarrollados que hayan ayudado al desarrollo económico y a la estabilidad social de las nuevas democracias, como por suerte para Portugal, España y Grecia, si tuvo la UE con Alemania y Francia.

Por ello, a falta de este desarrollo económico que acompañe y apuntale el desarrollo democrático, el gran problema para la consolidación de la democracia en toda Latinoamérica, 
pero más aún en Centroamérica, es la pobreza. Factor mantenido, en parte, por no contar con un socio poderoso que ayude a desarrollar sus economías en vez de esquilmarla, lo que en definitiva y salvando las distancias tuvo la Europa Meridional en la UE, incluso antes de la integración.

\section{Concertación entre actores políticos y sociales: Negociación y proceso de Paz}

La característica fundamental que iguala y define a todas las transiciones es la concertación entre los principales actores del proceso. Esto se repite en todas las transiciones, tanto en Europa Meridional como en el Cono Sur americano. Sin embargo, en Centroamérica, concretamente en El Salvador, Guatemala y Nicaragua, la negociación se produce, no ya entre gobierno y oposición, sino entre los contendientes de una guerra, el gobierno y el ejército regular por una parte, acompañado en ocasiones de grupos paramilitares y por otra parte los grupos armados opositores al gobierno, el Frente Farabundo Martí para la Liberación Nacional (FMLN) en El Salvador, la Unidad Revolucionaria Nacional Guatemalteca (URNG) en Guatemala y la Contra en Nicaragua.

Por tanto, la diferencia fundamental de la transición centroamericana con respecto a la española y las del resto del sur de Europa (Grecia y Portugal) e incluso de la mayoría de las latinoamericanas, es que Centroamérica debe salir de una guerra, la necesidad de acabar con el conflicto armado marca el proceso. Por ello, la existencia de la guerra civil da a este modelo una configuración particular: "Afirmamos que el carácter de la pacificación de la guerra explica la naturaleza de la transición y los resultados político-institucionales y económico-sociales que se van alcanzando"2.

Durante casi toda la guerra hubo intentos de negociación, sobre todo en El Salvador, aunque también en Guatemala, por ambas partes, que a tenor de los escasos resultados, como hemos señalado antes, parecían sobre todo intentos de ganar posiciones políticas y estratégicas ante el enemigo. Es a partir de 1990 tanto en El Salvador como en Guatemala, cuando se retoma el diálogo con visos claros de concluir en acuerdo.

Las razones que llevan a ello son tanto internas como externas, las causas internas son el cansancio de la guerra que ya acumulaba la sociedad centroamericana y el estancamiento

2 TORRES-RIVAS, Edelberto. "La pacificación de la guerra”, Foreign Affairs en Español, Verano 2001. [Publicación en línea], Disponible desde Internet en: <http://www.foreignaffairs-esp.org > [Con acceso el 26/04/2008] 
militar en el que ambos contendientes se daban cuenta ya de que era imposible vencer al enemigo militarmente. Las razones externas son fruto del fin de la guerra fría que deja a la guerrilla sin apoyos externos y hace que EEUU se plantee la inutilidad de mantener una guerra que deja ya de ser estratégica, por lo que posibilita e incluso presiona a estos gobiernos centroamericanos para que emprenda el camino del acuerdo.

En Nicaragua la situación es diferente, la derrota en 1990 del FSLN en las elecciones presidenciales abre la puerta a la coalición opositora, UNO (Unión Nacional Opositora) para llevar a cabo, con Violeta Barrios de Chamorro como presidenta, las reformas políticas y económicas que acaban con la guerra al satisfacer a la Contra y sobre todo a EEUU, único valedor de este grupo armado, llevándose a buen término y de forma rápida las negociaciones de desarme y desmovilización, acompañadas de la reducción del ejército sandinista y su transformación en un ejercito nacional no partidista.

Es en este nuevo contexto en el que se llega a la paz en Nicaragua, de la misma forma, tras más de dos años de diálogo y negociación se alcanzan los Acuerdos de Chapultepec firmados el 16 de enero de 1992, que llevan la Paz a El Salvador. Guatemala vive un proceso más lento y difícil pero finalmente, el 29 de diciembre de 1996 se firma el Acuerdo de Paz Firme y Duradera, que acaba con el conflicto.

Al partir de una guerra civil la transición será más complicada, ya que entran en el escenario una serie de variables que complican el proceso, como la desmilitarización de estas sociedades, la reducción de los ejércitos regulares y la desmovilización de los grupos armados. Además, debido a esta situación, las heridas están muy recientes y la concertación y el olvido son más difíciles aún.

Los procesos de paz en Centroamérica son, por tanto, el mayor ejemplo de concertación y moderación de las partes, ambos bandos deben ceder en sus posiciones tradicionales y llegar a un acuerdo, aunque no cederán en la misma medida. Un acuerdo que llega con las heridas de la guerra aún abiertas, con las barbaridades aún recientes.

Hay por tanto, dos factores clave que complican y hacen aún más loable la consecución de esta exitosa concertación, dos factores que no están presentes en los procesos del sur de Europa, aunque si en los del resto de Latinoamérica, pero sin llegar a los niveles centroamericanos. Por una parte, las reclamaciones de los represaliados que buscan justicia, esto no representó un problema en Europa, ya que la represión en los últimos años de estos sistemas dictatoriales 
no tuvo la intensidad que tuvo en sus primeros tiempos, pasó a ser una represión más selectiva y menos indiscriminada (aún manteniendo niveles brutales de violencia e injusticia, torturas, presos políticos, penas de muerte, etc...). En el Cono Sur americano si se dieron y de hecho siguen siendo un factor clave de confrontación que mantiene el proceso de transición abierto. Por otra parte, las diferencias sociales constituyen la otra gran dificultad del proceso, en Europa estaban más atenuadas y los niveles de vida eran más aceptables para la mayor parte de la población, lo que ayuda también a la moderación.

Sin embargo, en Centroamérica, con estos dos factores en contra, como hemos señalado, se produjo un ejemplo de moderación, sobre todo por parte de la izquierda.

El problema es que para hacer avanzar el proceso y llegar a los acuerdos se dejaron fuera estos dos factores, se mantuvieron casi al margen, sólo vagas declaraciones sobre el resarcimiento a las víctimas y la consecución de un desarrollo acompañado de justicia social, que quedaron rápidamente olvidadas. Pero es evidente que estos dos problemas son insoslayables, por lo que se han convertido, en dos graves problemas para la consolidación de la democracia.

\section{Desmovilización y desmilitarización}

El fin de la guerra dejó en Centroamérica sociedades altamente militarizadas, ejércitos sobredimensionados, grupos paramilitares y grupos armados opositores a los que se les debía dar una salida, primero mediante el desarme de los grupos irregulares y la reducción del ejército y luego posibilitando la integración en la vida civil de los desmovilizados. Con lo que la desmilitarización de las sociedades se transforma en un eje fundamental de los acuerdos de paz.

A esto hay que sumar que las nuevas democracias deben poner los cimientos para restar poder a los militares, acabar con sus injerencias en los asuntos políticos y conseguir la supeditación del poder militar al poder civil, redefiniendo las funciones encomendadas al estamento militar y llevando a cabo la necesaria reformulación de las fuerzas armadas y de su papel en la sociedad nacional y en el ámbito regional.

Por tanto, la tutela militar que ejercen los ejércitos de España, Brasil, Chile y en menor medida por su desprestigio tras la guerra de las Malvinas, Argentina, durante el proceso de 
transición, también se da en Centroamérica, pero con la variante de que aquí hay otra fuerza armada que hace de contrapeso y obliga, a cambio de su desmovilización, a la reducción paulatina de parte del ejército y a su salida del poder político.

Ayuda en este caso que en Centroamérica los regímenes vigentes a finales de los ochenta no son dictaduras militares como las de Chile, Argentina, Brasil o Uruguay, sino que son regímenes nominalmente civiles, aunque militarizados y con un fuerte poder de las fuerzas armadas debido a su hiperdesarrollo durante la guerra, y el apoyo a través de la ayuda militar de EEUU. Pero éstos regímenes, aunque torturan, asesinan y vulneran sin piedad los derechos humanos, tienen una estructura civil con elecciones, gobierno electo, teórica separación de poderes, etc. por lo que será menos traumático el cambio, que de hecho se produjo, aunque hubo que renunciar, en gran parte, a llevar adelante investigaciones sobre las atrocidades cometidas en los años de guerra y sólo fue posible llevar a cabo, comisiones de la verdad sin posibilidad de enjuiciamiento.

Por lo tanto, pese a que los ejércitos centroamericanos aún tienen gran poder y sobre todo una amplia autonomía sobre los asuntos militares y gozan de impunidad por las atrocidades cometidas, la reforma dentro de las instituciones castrenses y la desmilitarización progresiva de Centroamérica se puede contar entre los mayores logros del proceso de transición.

En la Tabla 1 podemos apreciar la disminución, desglosada en los tres cuerpos, de las fuerzas armadas, la disminución desde ejércitos hiperdesarrollados, fruto de una década de guerra y la ayuda exterior, de EEUU en los casos de El Salvador y Guatemala y de la URSS y Cuba en el caso de Nicaragua, se pasa en la década actual a ejércitos reducidos, mucho más acordes con la población y extensión de estos países. La reducción más significativa es la de Nicaragua, que ha pasado de tener el ejército más numeroso del istmo en 1989 a tener el más reducido en número en 2002. El contrapunto lo pondría Guatemala, que pese a la reducción de sus efectivos sigue teniendo un ejército considerablemente más numeroso que sus vecinos, resultado seguramente de la prominencia que aún tiene el ejército guatemalteco en el aparato estatal de su país. 
Tabla 1. Efectivos de las Fuerzas Armadas de El Salvador, Guatemala y Nicaragua, 1989-2002

\begin{tabular}{|l|c|c|c|c|c|c|}
\cline { 2 - 7 } \multicolumn{1}{c|}{} & \multicolumn{2}{c|}{ El Salvador } & \multicolumn{2}{c|}{ Guatemala } & \multicolumn{2}{c|}{ Nicaragua } \\
\cline { 2 - 7 } \multicolumn{1}{c|}{} & $\mathbf{1 9 8 9}$ & $\mathbf{2 0 0 2}$ & $\mathbf{1 9 8 9}$ & $\mathbf{2 0 0 2}$ & $\mathbf{1 9 8 9}$ & $\mathbf{2 0 0 2}$ \\
\hline Ejército de Tierra & 40,0 & 15,0 & 40,0 & 29,2 & 73,5 & 12 \\
\hline Marina & 1,3 & 0,7 & 1,2 & 1,5 & 3,5 & 0,8 \\
\hline Aviación & 2,2 & 1,1 & 1,0 & 0,7 & 3,0 & 1,2 \\
\hline Nota: Cifras en miles de hombres
\end{tabular}

Fuentes: Elaboración propia a partir de datos de: El Estado del Mundo. Anuario Económico y Geopolítico Mundial. Madrid, Akal, 1991, pp. 360-361 y 2004, pp.378-379

\section{Derechos Humanos e Impunidad ${ }^{3}$}

Durante las brutales guerras civiles que desangraron El Salvador, Guatemala y Nicaragua desde los setenta a los noventa, el mundo entero presenció impasible como en ese relativamente pequeño espacio, que es el istmo centroamericano, se producían las más brutales violaciones de los derechos humanos de que el hombre es capaz. Contamos con miles de testimonios que nos hablan de detenciones arbitrarias, desapariciones forzosas, malos tratos, torturas, violaciones, ejecuciones extrajudiciales y matanzas de pueblos enteros. Fueron los últimos años de la década de los setenta y los primeros de la de los ochenta los años más negros, años en los que "el mundo libre” enfrascado en su lucha contra el bloque socialista, alentó y ayudó militar y económicamente a los gobiernos que practicaban o encubrían las violaciones a los más elementales principios del derecho humanitario. EEUU apoyó sin reparos a gobiernos como los de Napoleón Duarte en El Salvador y Ríos Montt en Guatemala, a la vez que organizaba, entrenaba y financiaba a la Contra nicaragüense para imponer una guerra civil a la Nicaragua Sandinista.

3 Para un análisis de conjunto de los Derechos Humanos en Centroamérica a lo largo de la última década de paz ver: FERNÁNDEZ GARCÍA, Jesús. Derechos Humanos en Centroamérica. Balance de una Década de Paz (El Salvador, Guatemala, Nicaragua), [Publicación en línea], Centro de Estudios y Análisis de Seguridad, Universidad de Granada, 2002. Disponible desde Internet en: <http://www.ugr.es/ ceas/America Latina/Derechos Humanos en Centroamerica.pdf> [con acceso el 25-04-2008]; Son abundantes los Informes sobre Derechos Humanos de diferentes instituciones, entre ellas las más importantes son: la Comisión Interamericana de Derechos Humanos de la OEA, La Corte Interamericana de Derechos Humanos, el Instituto Interamericano de Derechos Humanos, el Alto Comisionado de Naciones Unidas para los Derechos Humanos, la Comisión para la Defensa de los Derechos Humanos en Centroamérica (CODEHUCA), Amnistía Internacional y Human Rights Watch. 
Es evidente que tras el fin de la guerra en estos tres países, las violaciones de los derechos humanos disminuyeron de forma espectacular, sobre todo en lo referente a los derechos más básicos, es decir, el derecho a la vida, a la libertad y a la seguridad e integridad de la persona, por lo que la situación actual en este campo es mucho mejor.

Hoy día, como atestiguan todas las organizaciones que vigilan el cumplimiento de los derechos humanos, se siguen produciendo en Centroamérica violaciones de los mismos como detenciones arbitrarias, torturas y malos tratos a manos de agentes policiales, pero la diferencia es que ahora no se producen de forma generalizada como parte de la política estatal contrainsurgente, como durante los años de guerra. Aunque esto no puede hacer que dejemos de denunciar estos claros abusos de los que los gobiernos son totalmente responsables, sobre todo de las violaciones de derechos humanos cometidas por agentes del Estado. Además deben ser los encargados de garantizar que se persiga, detenga y enjuicie a los culpables.

Los tres grandes problemas para estos tres países, hoy en día, en este terreno son: la impunidad, el acoso a los defensores de los derechos humanos y el incumplimiento de los más básicos derechos socioeconómicos y culturales.

La impunidad de los culpables de las atrocidades cometidas durante los años de guerra sigue siendo un lastre difícil de llevar para las sociedades centroamericanas, las personas responsables de las continuas violaciones de los más básicos derechos de sus conciudadanos, no sólo continúan libres sino que muchas de ellas mantienen altos cargos y gozan de amplias riquezas y mucho poder, como es el caso del general Ríos Montt en Guatemala. El hecho de que exista esta total impunidad ha contribuido a que se cometan nuevos y alarmantes abusos, dirigidos especialmente contra quienes tratan de combatirla, que sufren el acoso del gobierno y grupos relacionados con los responsables de la represión durante la guerra.

A estos dos problemas se unen nuevas preocupaciones como: la brutalidad policial, las condiciones penitenciarias deplorables, sobre todo la masificación de las cárceles, la violencia doméstica y las violaciones a los derechos laborales. En estos mismos años en Centroamérica han empeorado más aún las condiciones, ya de por si horribles, de las que partía en cuanto a los derechos sociales, económicos y culturales, lo que supone un lastre y un peligro de involución hacia la violencia, ya que como sostiene el Protocolo de San Salvador: "sólo puede realizarse el ideal del ser humano libre, exento del temor y de la miseria, si se crean condiciones que 
permitan a cada persona gozar de sus derechos económicos, sociales y culturales, tanto como de sus derechos civiles y políticos”4.

De entre estos factores, el problema de la impunidad se ha revelado como un factor de inestabilidad y de desprestigio para el nuevo sistema, que supone una grave rémora del pasado, este problema no es exclusivo de esta zona, pero si es de la máxima gravedad en la región, dado el nivel de violencia y sobre todo el nivel de extensión de esa violencia a lo largo de los años de la guerra, convirtiéndose en un lastre dejado por los procesos de transición que pretendieron esconder el problema y confiaron en el olvido.

\section{Conclusión: Consolidación Democrática o Desencanto Democrático}

De estos procesos de transición, que hemos definido anteriormente, derivan lo que calificaremos como democracias postransicionales, democracias que, aunque homologables con las democracias liberales occidentales, presentan una serie de características que han llevado a que se las defina con nombres tales como: democracias incompletas, democracias deficientes, democracias a medio hacer, democracias vigiladas, democracias de baja intensidad, democracias no liberales, democracias imperfectas o democracias inmaduras.

En todo proceso transicional se entrelazan los vectores de la continuidad y el cambio. En Centroamérica, es evidente que hay factores de continuidad e incluso limitaciones a la democracia instaurada y por supuesto muchos problemas para su consolidación, pero pese a ello es innegable el cambio, éste no se ve reflejado tanto en el cambio de las instituciones, ya que las estructuras democráticas ya fueron implantadas en los ochenta, sino que se produce al pasar de una democracia de fachada a llevar a la práctica esas estructuras democráticas preexistentes, pasando el Estado a abandonar sus políticas represivas y dando entrada en el sistema a la oposición política.

4 ORGANIZACIÓN DE ESTADOS AMERICANOS. Protocolo adicional a la Convención Americana sobre Derechos Humanos en Materia de Derechos Económicos, Sociales y Culturales, "Protocolo de San Salvador”. [Publicación en línea], 1988. Disponible desde Internet en: CIDH <http://www.cidh.org/Basicos/ Basicos4.htm> [con acceso el 26-04-2008] 
Todos los autores coinciden en que se han logrado, en los procesos de transición, una serie de objetivos fundamentales:

$\begin{array}{ll}\text { 口 } & \text { La paz: fin del conflicto armado. } \\ \square & \text { La desmilitarización. } \\ \square & \text { El fin del terrorismo de estado. } \\ \square & \text { El respeto a las libertades básicas y a los derechos humanos. } \\ \square & \text { La apertura a la participación democrática. }\end{array}$

Pese a las deficiencias que presentan estos logros, como la persistencia de violaciones de derechos humanos, aunque ya no como política de estado, o las limitaciones a la participación democrática, estos serían factores de cambio en el proceso. Frente a estos, los factores de continuidad serían la persistencia inmutable de las estructuras socioeconómicas que perpetúan las desigualdades, así como la persistencia de modos antidemocráticos en el desarrollo diario del sistema.

Los procesos de transición llevan aparejados la aceptación del binomio democracia liberal-libre mercado, por lo que la primera y clara limitación de las democracias producto de transiciones será la aceptación del modelo e instituciones de la democracia liberal occidental y de las reglas de libre mercado neoliberales, lo que supone desde un principio la negación de parte de la soberanía nacional y la autodeterminación, entendida como el derecho de toda sociedad a elegir su forma de gobierno y organización económica.

Pero la aceptación de estas limitaciones no son más que la aceptación del modelo triunfante en la guerra fría, homologando estos sistemas con las democracias occidentales. A esta aceptación de un modelo de sistema político, social y económico, habría que sumarle la aceptación de la vigilancia de su cumplimiento por parte de las potencias garantes del proceso, en el caso centroamericano, de EEUU, potencia regional que llevará a cabo un férreo control de su cumplimiento y exigirá la garantía de que sus intereses políticos y económicos en la zona no serán lesionados.

Estas limitaciones no son desde luego exclusivas de las democracias postransicionales, son los factores que marcan la democracia liberal allí donde se ha implantado, se resumen en restringir el juego político a aquellos que aceptan el sistema socioeconómico, apartando a través 
de campañas electorales costosas, sistemas de tendencia bipartidista y control de los medios de comunicación a los partidos u organizaciones que suponen un peligro para el sistema, dejando eso si, cierto margen para la protesta, cierto margen para la disidencia que demuestre la libertad y democracia del sistema.

Los logros de los procesos de transición en Centroamérica son evidentes, por cuanto se pasó de regímenes autoritarios y represores que despreciaban las libertades y los derechos humanos más básicos a sistemas que cumplen los requisitos mínimos de la democracia liberal. Los logros fundamentales, como hemos visto, son: la paz, como fin del conflicto armado, la desmilitarización, el respeto a las libertades básicas y a los derechos humanos y la apertura del sistema a la participación democrática.

La guerra, que desangró la zona, fue finiquitada tras una serie de exitosos procesos de paz, aunque la violencia política ha sido sustituida por la violencia social, la criminalidad común. El fin de la guerra posibilitó la desmilitarización de las sociedades del istmo, tanto por el desarme y desmovilización de los grupos armados opositores como por la reducción tanto en número como en intromisión en las instituciones y el poder político de las fuerzas armadas centroamericanas, pasando éstas a ocupar una posición supeditada al poder civil, como es común en las democracias occidentales, aunque aún mantienen importantes cotas de autonomía en asuntos militares.

El respeto a las libertades básicas y a los derechos humanos, constituye un hito fundamental en países en los que en la década anterior éstos fueron brutalmente pisoteados, aún se producen hechos denunciables y la impunidad que han logrado aquellos que masacraron a sus pueblos durante una década supone un lastre para los nuevos sistemas, pero al menos la represión y la violencia política ya no son políticas de estado.

La apertura a la participación democrática es quizás el punto que provoca más controversias y en el que es más difícil evaluar los logros, es cierto que se han puesto los ladrillos fundamentales de un sistema de democracia liberal homologable con los occidentales, sin embargo, las carencias en cuanto a un sistema de partidos bien constituido, las limitaciones a la competencia, en base a las posibilidades que otorga el sistema electoral, a la financiación de los partidos y el desigual acceso a los medios de comunicación de masas, serían los puntos oscuros de esta apertura. Pero son las restricciones con las que se encuentran los gobiernos para llevar a cabo sus políticas, sobre todo en cuanto a las medidas económicas, que vienen determinadas por los organismos internacionales, la mayor limitación del sistema. 
Estos logros son, en si mismos, un paso fundamental para el desarrollo político de la región, aunque cada uno de ellos presente zonas de oscuridad, principalmente la apertura y la participación política, ya que aún no se han logrado consolidar los sistemas democráticos que constituyeron el esperado fruto de la paz y la transición.

Pero por encima de estos problemas de la democracia, el mayor factor de inestabilidad es la enorme desigualdad social, ésta ha provocado el descontento popular con el sistema socioeconómico y político producto de la transición que no sólo no ha sido capaz de mejorar sus condiciones de vida sino que las ha empeorado, disparando además altos índices de violencia social, esto junto con los, ahora más visibles, niveles de corrupción, ha provocado la crisis de confianza en el sistema democrático surgido en los noventa. Lo que ha impedido la consolidación democrática, llevando a Centroamérica al desencanto.

De hecho, el cada vez mayor desencanto y alejamiento de los ciudadanos de la política constituye un grave riesgo para el sistema. El desprestigio de la política y los políticos por su incapacidad a la hora de resolver los problemas sociales de la población y sus continuos escándalos de corrupción han llevado a este alejamiento que se traduce en alarmantes cifras de abstencionismo.

Son por tanto, democracias que, aunque pueden parecer sólidas, tienen los pies de barro debido a la desigualdad y la injusticia reinantes, ya que, un sistema democrático depende de la aceptación mayoritaria de la población y ésta no se da sin unas mínimas condiciones de vida que garanticen los derechos económicos y sociales básicos.

Por ello, el consenso necesario para la democracia se ha ido perdiendo de forma alarmante, como señala Zamora: "El espíritu optimista que prevalecía al abrirse la posguerra ha cedido el espacio a una mezcla de cinismo y amarga resignación”

Es cierto que el desencanto y la frustración se dan, hoy día, en la mayoría de los países democráticos:

“existe una desilusión generalizada con los procesos democráticos. En la mayoría de los países occidentales los niveles de confianza en los políticos han caído en los últimos años. Vota menos gente que antes, particularmente en Estados Unidos. Cada vez son más quienes dicen no

$5 \quad$ ZAMORA, Rubén Ignacio. "Participación y democracia en El Salvador”, En: CÓRDOVA MACÍAS, Ricardo; MAIHOLD, Günther; KURTENBACH, Sabine (Comps.), Pasos hacia una nueva convivencia: democracia y participación en Centroamérica, San Salvador (El Salvador), FUNDAUNGO, 2001. pp. 67 
tener interés en la política parlamentaria, especialmente entre las generaciones jóvenes”6.

Esto ocurre, aún más claramente, en los países que han llegado a la democracia a través de procesos de transición, de hecho en España no tardó en producirse también, la idealización de la democracia como un sistema que cambiaría y mejoraría la situación socioeconómica y las esperanzas puestas en ella, llevaron luego al desencanto, el mismo que hoy se vive en Centroamérica, la diferencia fundamental la constituye la pobreza, el cinismo con que se ve a los políticos en España, se traduce en Centroamérica en desesperación por la dramática situación de las condiciones de vida de amplios sectores de la población y la violencia e inseguridad económicas que ello genera.

Por tanto, la cuestión básica sería si puede un sistema democrático consolidarse si no va de la mano del desarrollo económico, si la gente tiene las necesidades cubiertas será más receptiva al pacto, a la concertación y la moderación que en una situación de miseria en la que es necesario reivindicar más y radicalizarse más, en este sentido en América Latina no se dan las condiciones económicas que hagan posible democracias estables.

Como plantea Ricardo Ribera refiriéndose a El Salvador: "Como país y en el marco del proceso histórico más general, los tiempos de revolución (y contrarrevolución) han sido superados y sustituidos por estos tiempos de reforma, la cual amenaza siempre ser desbordada por la revuelta ante la falta de alternativas radicales a los radicales problemas no resueltos”7.

Las desigualdades sociales y económicas, las condiciones sociales y económicas que condujeron a las guerras de la década de 1980 no han sido resueltas, con la democracia se han soslayado, y se han abierto huecos por los que protestar que están sirviendo de salida, de válvula de escape para la presión, pero que no desactivan la bomba de relojería que supone la situación.

Desde el discurso del poder se nos intenta vender la democracia como la meta final, como la consecución del sistema perfecto que hay que alabar, pero la democracia liberal no es sinónimo de desarrollo económico, esta última década lo demuestra terriblemente en Centroamérica, donde saben, ya que lo viven en su día a día, que es necesario continuar la lucha por una sociedad más justa, más participativa, en suma más democrática, para que la democracia sea real y no una ficción adormecedora, para que la democracia resuelva realmente sus problemas.

6 GIDDENS, Anthony. Un Mundo Desbocado. Los efectos de la globalizacion en nuestras vidas. Madrid, Taurus, 2000. pp. 85

$7 \quad$ RIBERA, Ricardo. De la guerra a la paz. Análisis dialéctico del proceso histórico salvadoreño, Universidad Centroamericana, El Salvador, Enero 2002. [Publicación en línea], Disponible desde Internet en: $<$ http://www.uca.edu.sv/facultad/chn/c1170/delaguerraalapaz.html> [Con acceso el 10/04/2008] 
Es evidente, por tanto, que son los lastres de actitudes autoritarias y la impunidad de los represores, es decir, los temas aún no zanjados desde la guerra y sobre todo las tremendas desigualdades económicas, los factores de riesgo para las incipientes democracias y por tanto para la paz social en la actual Centroamérica.

Lo que está claro y en lo que coinciden la mayor parte de autores, es en que las causas de la guerra, fundamentalmente la injusticia social, siguen estando presentes en Centroamérica, esos conflictos sólo están aplacados o adormecidos, no resueltos, por lo que si los problemas políticos, económicos y sociales, no son enfrentados, reaparecerán creando nuevos conflictos que pondrán en peligro la paz que se logró en los años noventa. En palabras de Rubén Zamora:

"Pero lo que no puede dejarse a un lado es que tarde o temprano, los elementos contradictorios en las relaciones políticas, económicas y sociales que hemos señalado, tenderán a expresarse en conflictos sociales e inestabilidad. Efectivamente la historia de nuestro continente está plagada de ejemplos, por lo general trágicos, de procesos de apertura política que terminan en dictaduras autoritarias al chocar con las realidades de una economía rígida.”.

Por último, pese a todas las carencias que hemos señalado, es evidente la mejora de la región en estos años sin guerra, con mayor pluralismo político y mayor respeto por las libertades básicas y los derechos humanos. La gran asignatura pendiente es buscar esa transición económica que permita salir de la situación de miseria que impide el desarrollo de la democracia, ya que ésta no es posible sin unos mínimos niveles de igualdad económica que permitan el desarrollo humano en condiciones dignas. Espero que las sociedades centroamericanas sepan, puedan y les permitan avanzar en ese camino, ya que como escribió Héctor Pérez Brignoli, refiriéndose al pueblo centroamericano: "no es posible creer que merezcan otra primavera interrumpida”"

8 ZAMORA, Rubén Ignacio. "Participación y democracia en El Salvador”, En: CÓRDOVA MACÍAS, Ricardo; MAIHOLD, Günther; KURTENBACH, Sabine (Comps.), Pasos hacia una nueva convivencia: democracia y participación en Centroamérica, San Salvador (El Salvador), FUNDAUNGO, 2001. pp. 75 9 PÉREZ BRIGNOLI, Héctor. Breve Historia de Centroamérica. Madrid, Alianza, 1985. pp. 156 